Gut, 1960, 1, 87.

\title{
CROHN'S DISEASE (REGIONAL ENTERITIS) OF THE LARGE INTESTINE AND ITS DISTINCTION FROM ULCERATIVE COLITIS
}

BY

\author{
H. E. LOCKHART-MUMMERY and B. C. MORSON
}

\section{From the Research Department, St. Mark's Hospital, London}

Twenty-five cases of Crohn's disease (regional enteritis) of the large intestine are described and illustrated. The clinical and pathological criteria for this diagnosis are discussed with emphasis on the distinction from ulcerative colitis. Suggestions are made regarding the surgical treatment of these patients.

The pathogenesis of many of the inflammatory diseases of the large intestine is imperfectly understood and the literature contains many conflicting views, and so no classification has been generally accepted. Apart from specific diseases such as diverticulitis, bacillary dysentery, amoebic dysentery, and lymphogranuloma venereum, there remains to be considered a group of conditions which have been given an abundant and confusing nomenclature. These include such expressions as "regional colitis", "right-sided colitis", "segmental colitis", "enterocolitis", "ileocolitis", "ulcerative colitis", and "regional enteritis", all of which are largely the result of attempts at classification based on clinical research. Some authorities, notably Goldgraber and Kirsner (1958); Goldgraber, Kirsner, and Palmer (1959) favour a unified approach to these conditions based on aetiological theories of hypersensitivity or auto-immune disease. Others have attempted to classify them more accurately by study of the gross and microscopic appearances in surgical material, correlating the clinical and pathological appearances, and, as a result, the conditions we call "chronic ulcerative colitis" and "regional enteritis or Crohn's disease" have become more definite clinical-pathological entities in recent years. Apart from staphylococcal enterocolitis the other expressions referred to above, such as "segmental colitis" and "ileocolitis", are valueless from the point of view of classification based on pathogenesis. Moreover, they have added to the general confusion because different authors use them to refer to differing pathological conditions.

In this article we describe a clinico-pathological study of 25 patients with localized or diffuse inflammation of the large intestine whom we believe to have the same disease as that described by Crohn, Ginzburg, and Oppenheimer in 1932. In order to avoid further confusion we have preferred to use the eponymous term "Crohn's disease of the large intestine", because our patients had the same characteristic pathology in the large intestinal lesions as that described by Hadfield (1939) for the disease as it affects the small intestine. The fact that Crohn's disease could affect the colon was first mentioned by Colp in 1934 and noted by Crohn and Rosenak in 1936. Since that time there has been much confusion over the relationship between Crohn's disease and ulcerative colitis. This expression "Crohn's disease of the colon" was first used by Wells (1952) and later by Brooke (1959). It is not our purpose to go into the aetiological factors which may be common to these two diseases, but only to emphasize that Crohn's disease of the large intestine and chronic ulcerative colitis can be distinguished on clinical and pathological evidence and that this may have therapeutic implications.

The 25 patients with Crohn's disease of the large intestine presented here were treated at St. Mark's Hospital during the five-year period 1955-1959, and in all of them operation specimens have been available for pathological examination. Our experience with the pathology of this condition has been augmented, however, by the examination of a further nine operation specimens of Crohn's disease affecting the large bowel from patients who received surgical treatment at other hospitals during the same period. Cases of recurrent Crohn's disease at or distal to the ileocolic anastomosis after surgical resection for disease of the small intestine have been excluded from this study. During the same five-year period, 156 patients with chronic ulcerative colitis 
were treated surgically at St. Mark's Hospital; 20 cases of Crohn's disease affecting the small intestine only have also been seen, as well as four cases of "regional colitis" in which there were no pathological features to suggest Crohn's disease. When considering these figures, it must be remembered that St. Mark's is a special hospital for diseases of the colon and rectum to which patients with disorders of the large bowel are likely to be referred, so a particularly high proportion of involvement of the large bowel among the cases of Crohn's disease seen there is not as surprising as it would appear, nor do we suggest that our figures are representative of the distribution of Crohn's disease generally. We recognize now that cases of this condition have been seen at this hospital more than five years ago, but at that time they were not recognized as being cases of Crohn's disease of the colon, and in many of them neither the pathological material available nor the clinical notes were as full and adequate as are available nowadays. We have, therefore, excluded these cases from this presentation.

\section{Classification and Case Reports}

In a previous paper (Morson and LockhartMummery, 1959a) we classified some of these 25 cases into two main groups, namely, (1) diffuse disease of the colon and (2) strictures of the colon. This classification was based on the location of the intestinal lesions in operation specimens. Further experience has confirmed that this is a useful subdivision, but in this paper we are also presenting as a separate group some patients in whom the disease has predominantly affected the rectum. We have therefore classified them as follows:

(1) Diffuse Disease of LARge INTESTine.-Most or the whole of the large bowel was diseased, in the majority of cases, with patches of normal mucosa. This group of 13 cases was further subdivided according to the presence or absence of similar disease in the terminal ileum.

(2) LoCalized Disease.-Patients with only a short segment of the colon affected or more often with multiple strictures and extensive areas of normal intervening mucosa: there were six patients in this group.

(3) Disease Mainly Confined to Rectum.There were six patients in this group.

Diffuse Disease of LaRge INTESTINe.-Of the 13 patients in this group there were nine men and four women. Six, all of whom were men, had involvement of the terminal ileum. Cases 4 and 7 were brothers, aged 22 and 27 , but only one of them had disease of the terminal ileum. The average age of this group of cases was 27 years at the time of treatment, the youngest being 17 and the oldest 49, 10 of them being under 30 . The duration of their symptoms from onset to the time of treatment varied from six months to 12 years, but in the majority it was between one and two years. The youngest patient was $15 \frac{1}{2}$ years at the time of onset of symptoms and the oldest was 47 years old.

The extent of the disease in these patients is shown in Figs. 1 and 2, Fig. 1 showing those cases with involvement of the ileum as well as the colon, and Fig. 2 those in which the terminal ileum and the rest of the small bowel were quite normal. It will be seen from Fig. 1 that Case 1 is the only patient in whom the whole of the large bowel was involved as well as the small bowel, and as he presented many features which we now believe to be typical of this condition, we present his history in some detail.

Case 1.-This young man was 19 years old when first seen in 1948. He was referred because of an anal fistula and gave a history of anal disease with some diarrhoea for six months. At this first examination sigmoidoscopy was normal but he had a complex anal fistula, clinically tuberculous, and was admitted for operation. The fistula was operated on a few weeks later and giant cell systems were found in biopsy material. A diagnosis of tuberculous fistula-in-ano was made at that time, but the patient did well and the fistula healed within three months. A chest radiograph was normal. He was seen annually between the years 1949 and 1954 and remained well except that he had mild diarrhoea with his bowels acting two to three times a day, passing a semi-formed motion. In 1954 he suddenly became very much worse, with intense diarrhoea, pyrexia, loss of weight, and some blood in the motions. At this time, sigmoidoscopy showed a granular rectum and it was noted that the anal fistula had recurred. Barium enema examination showed a generalized contraction and polypoid appearance of the large bowel. A search was made for tubercle bacilli, both by staining and culture methods and by guinea-pig inoculation, but proved negative. The patient was regarded as a case of severe ulcerative colitis, and as there was no response to medical treatment a laparotomy was done with a view to colectomy. At operation the ileum as well as the colon was found to be diseased, and several inches of the terminae ileum were therefore removed with the whole of the colon and an ileostomy established. Three months later the remaining recto-colic segment was excised. The patient made a good immediate recovery but the perineal wound took several months to heal. However, at the time of writing, five years after his operation, he is very well, working full time and with a normally functioning ileostomy.

The operation specimen is shown in Fig. 3. There is disease of the terminal ileum with extensive involvement of the colon and the appearances are similar to those 


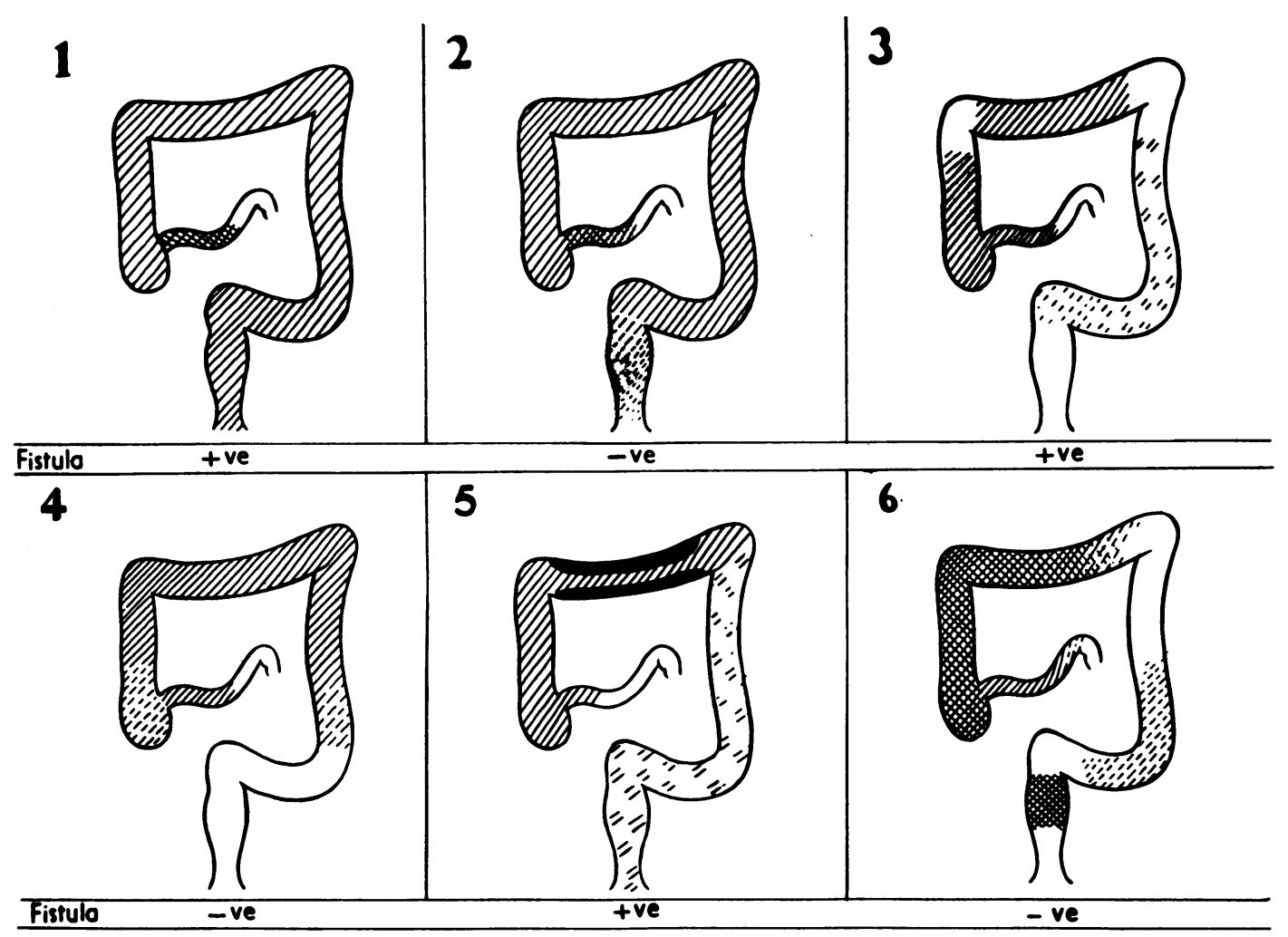

Fig. 1.-Cases 1-6. Diffuse disease of the large intestine with involvement of the terminal ileum.

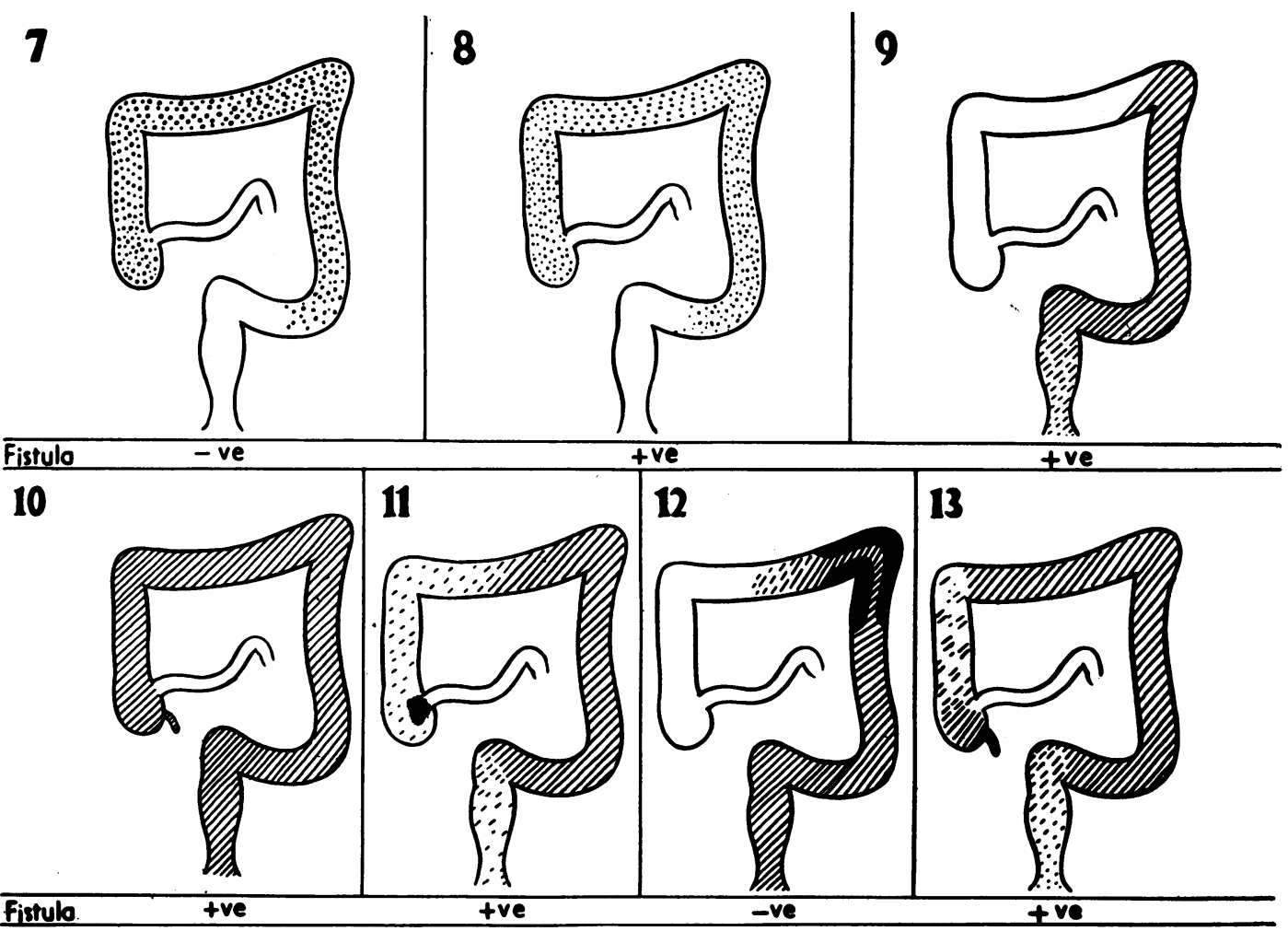

FIG. 2.-Cases 7-13. Diffuse disease of the large intestine with normal terminal ileum. 


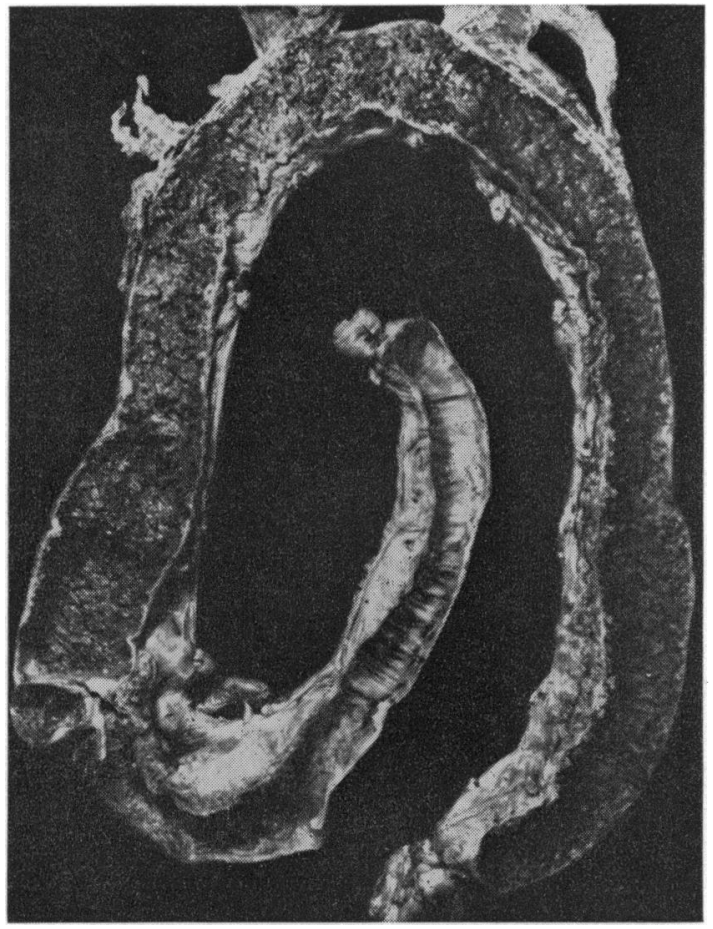

FIG. 3.-Operation specimen from Case 1. There is a contracted terminal ileum with mucosal ulceration especially in the distal six inches and thickening of the bowel wall. The ileo-caecal lymphatic glands are grossly enlarged. The appearances of the colon are similar to those seen in ulcerative colitis with inflammatory polyposis.

seen in ulcerative colitis. However, the histology of both the terminal ileum and of sections taken from different parts of the colon showed appearances characteristic of Crohn's disease.

It is not surprising that five of these 13 patients had been regarded as cases of ulcerative colitis at some time during their illness, and that a further three patients had been regarded as suffering from tuberculous colitis, largely because of the clinical appearance of the anal lesions. Case 10, a patient who had extensive anal ulceration, was treated originally at this hospital by a sigmoid colostomy, but developed undermining ulceration around the stoma, which seemed to confirm the tentative diagnosis of tuberculosis.

Localized Disease.-Of the six patients in this group there were four men and two women. The terminal ileum was diseased in one of the male patients only.

The average age of this group was 54 years, the youngest patient being 34 at the time of treatment and the eldest 72 . The duration of symptoms varied from one year to seven years before surgery was undertaken, but in three of the six symptoms had been present for one year only, although one of these three had had two anal fistulae 18 years and 12 years before the onset of diarrhoea.

The extent and distribution of the disease in these six patients is shown in Fig. 4. It will be seen that the disease is patchy in its distribution, short segments of diseased bowel being separated by relatively long segments of normal intestine. In all six patients the areas of disease had led to narrowing of the lumen which in a few of them was sufficiently severe to be called a definite stenosis. Obvious ulceration in the diseased areas was only seen in two of the six operation specimens, the others showing thickened muscle, fibrosis, and stenosis. The gross appearance gives the impression of a more inactive, "burnt-out" disease than in the operation specimens of the diffuse group. This observation is in keeping with the older average age of these patients, but the duration of symptoms is much the same in the two groups; it is possible that in these patients the symptoms resulted from the stenosis rather than from active disease. Case 14 is a good example of this group of patients.

Case 14.-This man was first seen at St. Mark's Hospital in 1955 at the age of 69 . He had diarrhoea in 1951 with an ulcer in the rectum. In 1953 he had a laparotomy for a large bowl lesion but no resection or anastomosis. In 1955 he complained of increasingly severe diarrhoea with blood in the stools and some degree of incontinence. Examination of the rectum showed pus in the lumen and a curious granulomatous lesion in the middle rectum. A barium enema showed a filling defect in the transverse colon. Another laparotomy was done and the only abnormality in the abdomen was a localized lesion in the middle of the transverse colon which appeared to be inflammatory. The rest of the large bowel and all the small bowel appeared normal but the upper rectum felt somewhat thickened. A resection of the transverse colon with immediate end-to-end anastomosis was carried out. The patient did well after the operation but remained incontinent and the lesion in the rectum seemed to be getting rather worse. Accordingly, a left inguinal colostomy was established. From then on the patient made good progress and gained weight but the lesion in the rectum caused progressive stenosis and it has never been possible to close the colostomy. At the time of writing, four years after the operation, the patient is well and with a satisfactorily acting colostomy, but with considerable stenosis of the rectum.

The specimen of the lesion removed by resection of the transverse colon is shown in Fig. 5. It shows obvious narrowing of the lumen and thickening of the bowel wall over a distance of about 4 in. The histological appearances were those of Crohn's disease.

In one of these patients (Case 15) a diagnosis of 


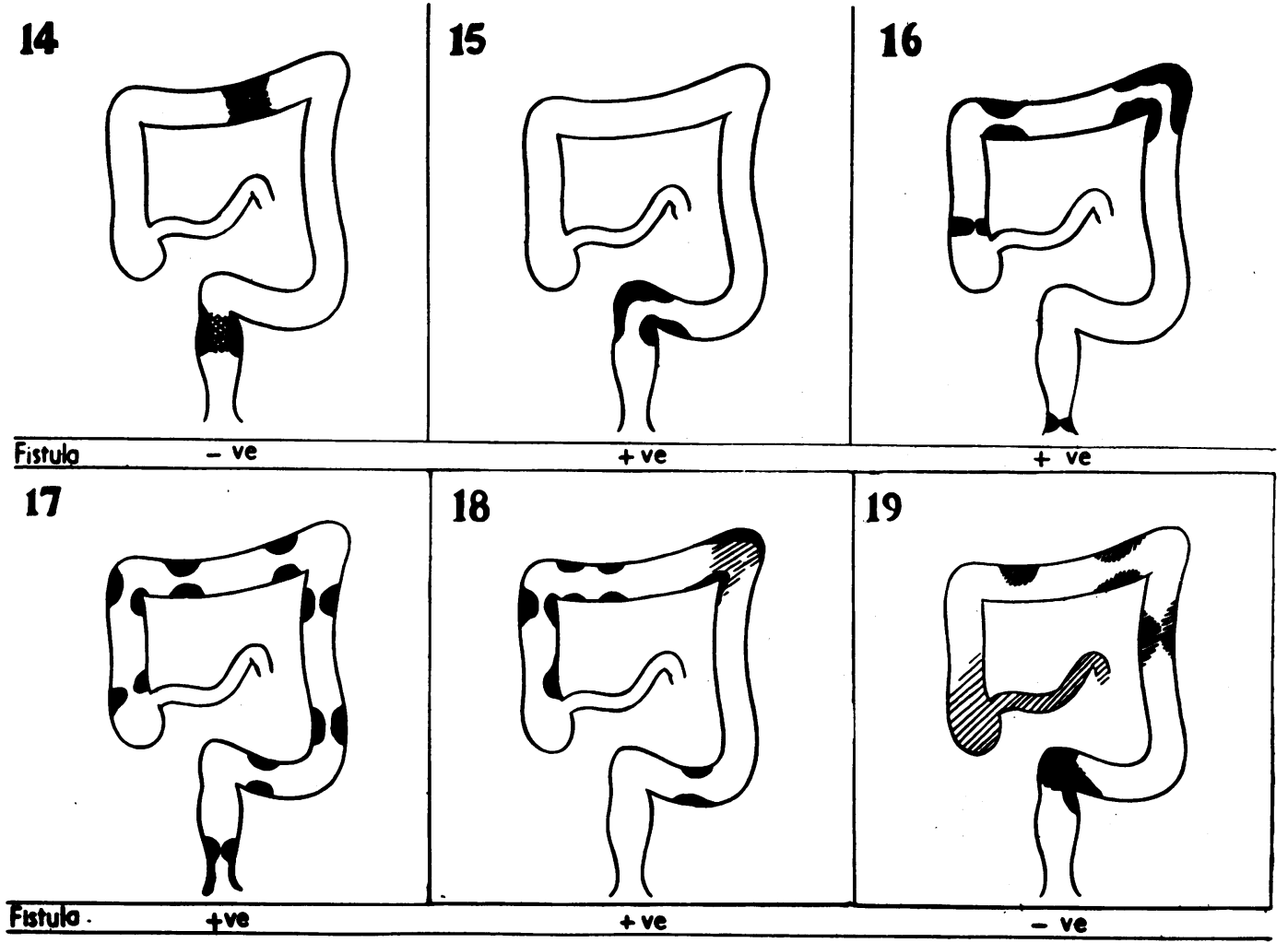

Fig. 4.-Cases 14-19. Localized disease of the large intestine presenting in the form of multiple strictures. There is associated disease of the small intestine in only one case, No. 19.

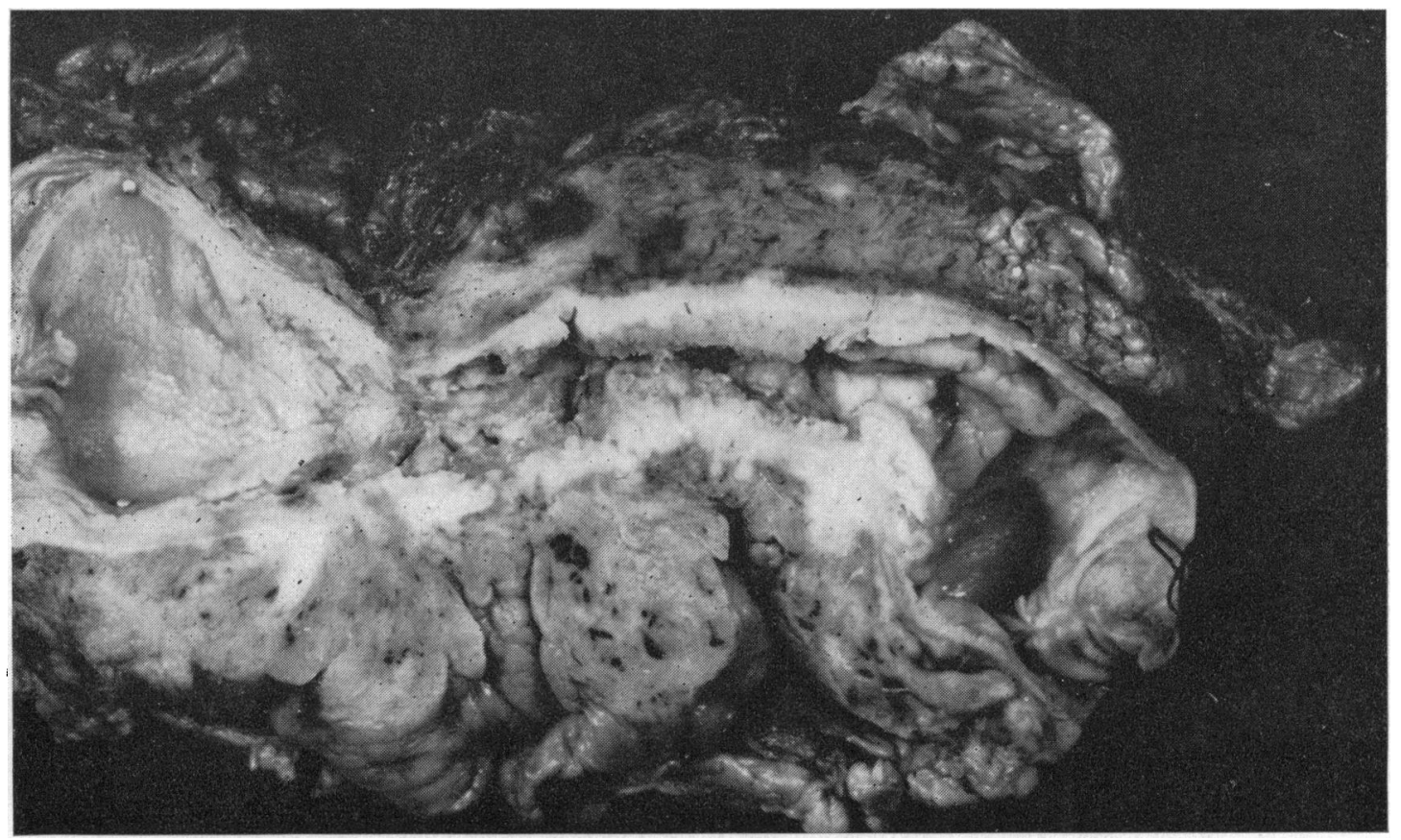

Fig. 5.-Colectomy specimen from Case 14. The lumen is narrowed and the wall thickened over a segment of transverse colon about 4 in. long with extension of the granulomatous process into the pericolic fat. 


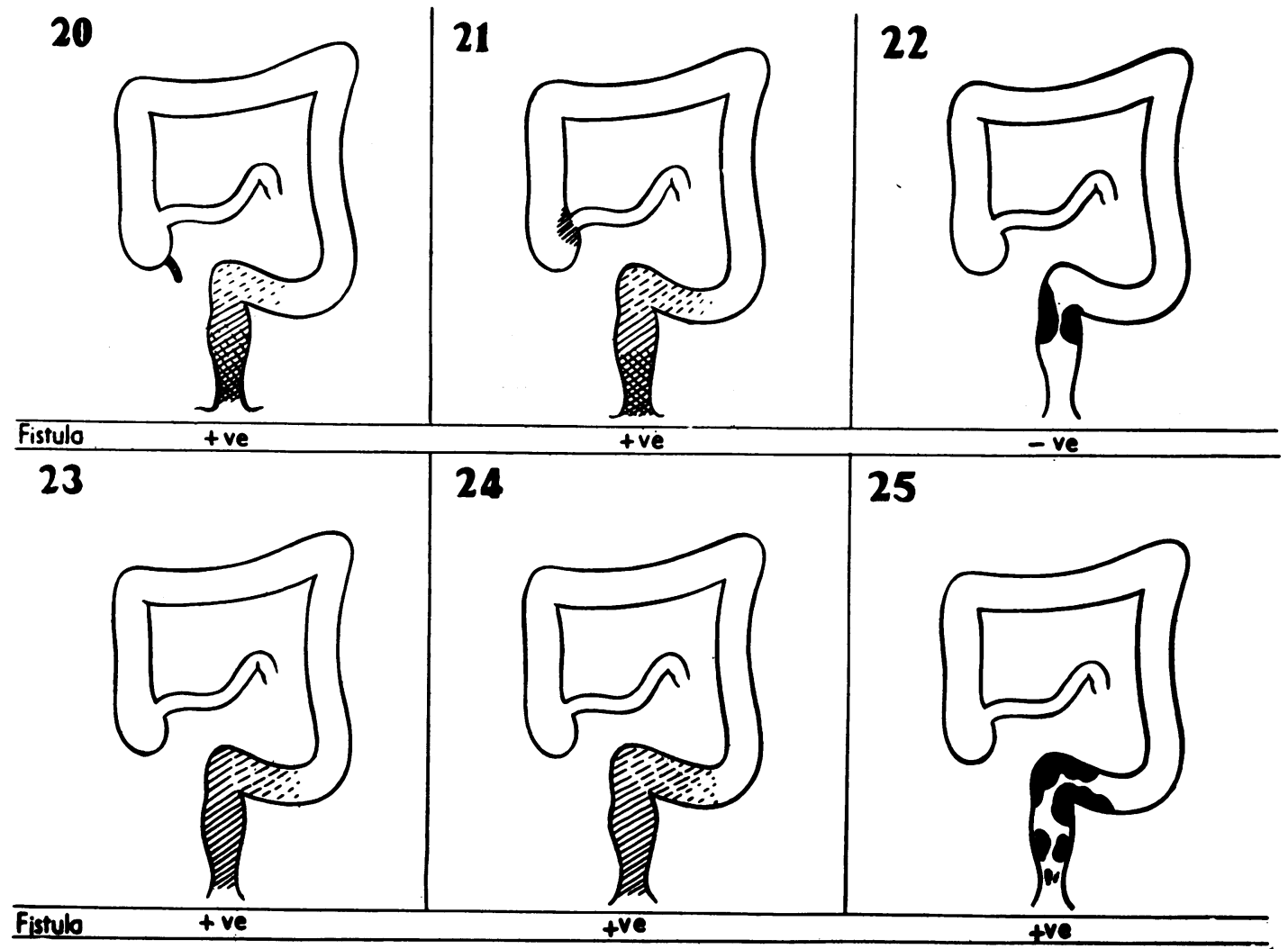

Fig. 6.-Cases 20-25. Disease mainly involving the rectum and rectosigmoid region. Two cases also had disease of the appendix (Case 20) and ileo-caecal valve (Case 21).

"tuberculous colitis" had been made previously, partly because of the presence of two sinuses in the left loin and partly because of an anal fistula with an indolent appearance. Case 16 had been diagnosed as "ulcerative colitis" during her first attack, five years before treatment at St. Mark's. In the other patients the diagnosis was uncertain in the early stages and was only made by pathological examination of a piece of resected colon.

Disease Mainly Involving the Rectum.There were six patients, four men and two women, in whom the disease predominantly affected the rectum and rectosigmoid region. The average age was 43 years, the youngest being 15 and the oldest 56. The duration of symptoms varied from six to 12 months, but one patient had had symptoms for three years.

The extent and distribution of the disease in this group is shown in Fig. 6 . It will be seen that two patients (Cases 23 and 24) had involvement of the rectum and lower sigmoid colon only. Two others had a similar distribution of disease but with isolated lesions of the appendix in one case and the ileocaecal valve in the other. One patient had a single localized stricture of the rectum. Case 20 is a good example of this group of patients.

Case 20.-This youth was first seen at St. Mark's Hospital in October, 1957, when he was 15 years old. He gave a history of diarrhoea for the previous six months, passing two to four loose, offensive stools daily. A trace of blood had been noticed on one occasion only. He had lost about a stone in weight, and had felt generally rather unwell. Examination showed him to be rather pale and sallow, but abdominal examination revealed no abnormality. The perianal region was oedematous, inflamed, and tender, with superficial tender cracks and a fistula discharging pus. There was some stenosis at the level of the anorectal ring and examination caused pain. Sigmoidoscopy under anaesthesia showed patchy areas of oedematous granular mucosa and scattered ulcers in the rectum, with pale normal mucosa between the affected parts. There was much free pus in the lumen. A chest radiograph and a barium enema were both normal.

Biopsy from the anal fistula showed giant-cell systems, but no tubercle bacilli could be demonstrated. Never- 
theless, he was thought to have a tuberculous infection, and was transferred to a sanatorium near his home. In spite of general measures and treatment with streptomycin, I.N.A.H. and prednisone, however, the anorectal condition increased in severity and several perianal abscesses formed which required drainage. A left inguinal colostomy was established in March, 1958, but led to only slight improvement. At this time repeated culture of the pus from the rectum and guinea-pig inoculation were negative. Laparotomy was carried out in October, 1958, but all viscera were found to be normal apart from the lower sigmoid colon and rectum which were thickened; a biopsy from the perirectal tissue was taken. Sections again showed non-caseating giant-cell systems, and a diagnosis of Crohn's disease appeared to be most likely.

He was readmitted to St. Mark's in January, 1959, having by then developed considerable anal stenosis with several undermined painful anal ulcers. The disease appeared to be confined to the rectum and anus, and there seemed to be no useful alternative to excision of this part of the bowel. This was done by combined excision, the sigmoid colon being removed up to the colostomy, which was converted to a terminal one. All other viscera appeared normal, except that the spleen was somewhat enlarged, but the appendix was removed. Recovery was delayed by an attack of intestinal obstruction, but was thereafter uneventful, and now a year later he is in excellent health, without symptoms, and working full time.

The specimen (Figs. 7 and 8) showed oedema and scattered ulceration of the whole rectal mucosa, with a large ulcer in the lower third. There was considerable fibrous thickening of the wall in the lower part of the rectum, and many anal fistulae were found. Histology both in the bowel wall and in the lymph nodes was typical of Crohn's disease, and similar changes, including giant-cell systems, were found in the appendix.

Three of these six patients were at first regarded as cases of procto-colitis. This diagnosis was later changed to "tuberculous colitis" in two of them when fistulae developed in which giant-cell systems were found, and two other patients had been diagnosed as cases of tuberculosis on the evidence of anal lesions. In Case 22 the hard and localized nature of the lesion led to a clinical diagnosis of rectal carcinoma, and although biopsy was negative, excision of the rectum was advised and carried out in the belief that the lesion was due to the submucous spread of a rectal cancer. A study of Figs. 1, 2, 4, and 6 will show that the grouping of these cases is not exact. For instance, Case 22 may have more in common with the patients in Group 2 than with those in Group 3, and Case 19 in Group 2 is very similar to those in Group 1. We emphasize, however, that we are not attempting to set forth an accurate classification but only to present a series of cases in a coherent and intelligible way. It may be that further experience and study of a larger series of cases over the next years will suggest a classification which will be more exact and acceptable.

\section{Summary of Clinical and Radiological FINDINGS}

History.-Diarrhoea is by far the most common symptom and was present at some time in all our cases, and in the majority was at all times the main complaint. According to the extent and severity of the disease, it varied from mild to severe and was in most cases continuous, but was in some recurrent with periods of remission. In those cases with strictures of the colon, attacks of diarrhoea were usually accompanied by some abdominal colic, although abdominal pain was not the main complaint in any patient; while in those patients with disease affecting mainly the rectum, morning diarrhoea and urgency were frequent features. Passage of blood in the stool was not common and was usually only mentioned as a symptom by those with disease involving the rectum. Loss of weight was a feature of many cases and a general malaise and lethargy were frequently revealed on questioning. In those patients admitted with an acute relapse, pyrexia was common.

ANAL LESIONS.-A very high proportion of these patients, 17 out of the 25 , had at some time during the course of their illness a lesion of the anus or perianal region (see Figs. 1, 2, 4, and 6). As might be expected, they were particularly common in those patients with disease involving the rectum, though not confined to such patients. A few of the patients gave a history of having had an anal fistula in the past, but in a larger number an anal lesion was present when the patient was first seen at the hospital. The commonest lesion was an anal fistula which was often, but not always, indolent and lacking in induration, but curious undermining anal ulceration were seen in a few patients, and others had anal fissures that appeared indolent and infected. Often there was oedema of the skin of the perianal region and frequently the anal lesion was extremely painful.

In some patients the anal lesion had been the first sign of disease, and in Case 11 a large and painful ulcer at the anus remained throughout her illness the most distressing symptom, though diarrhoea and weight loss occurred later. In most other patients diarrhoea or other bowel symptoms preceded the onset of an anal lesion, in one case by 12 years; in some cases the anal lesion appeared about the same time as the bowel symptoms started.

The association of anal lesions with intestinal Crohn's disease is well known but we wish to draw 
Fig. 7.-Case No. 20. Operation specimen of abdominoperineal excision of lower sigmoid colon, rectum, and anal canal, showing ulceration and stenosis of the lower third of the rectum with a nodular condition of the mucosa of the upper rectum and sigmoid colon due to granulomas in the submucous layer.

Fig. 8.-Close-up of Figure 7.

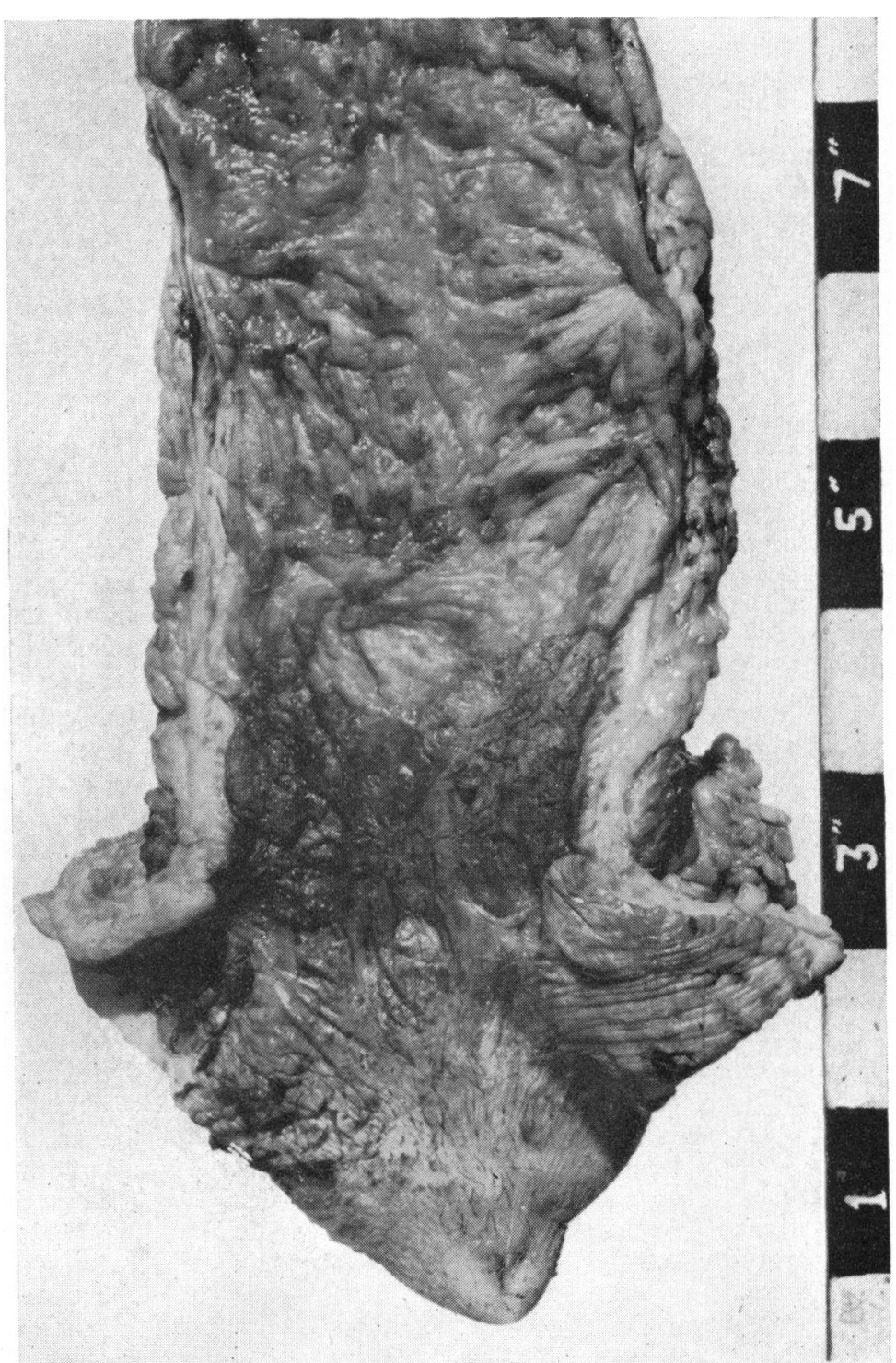


attention to the particularly high incidence of this complication in cases of Crohn's disease in which the large bowel is affected (Morson and LockhartMummery, 1959a and b).

Sigmoidoscopy.-As can be seen from Figs. 1, 2,4 , and 6 , in many of these 25 patients the disease did not extend to the rectum, and in most such patients the rectum was perfectly normal on sigmoidoscopy, although in a few of them slight oedema was noticeable. In most patients in Group 2, the lowest stricture could either be felt with a finger or reached with the sigmoidoscope; the mucosa was usually normal as far as the lower border of the stricture, at which level the bowel could be seen to be reddened, narrow, and rigid. Actual ulceration at the stricture could sometimes be seen, and where an active ulcerative lesion was present pus was seen in the lumen of the bowel.

In those patients of Groups 1 and 3 in whom the bowel was extensively involved, definite abnormalities of the rectal mucosa were found on sigmoidoscopy. In some of them the appearance was that of a uniformly granular bowel, bleeding on touch, and apparently indistinguishable from that

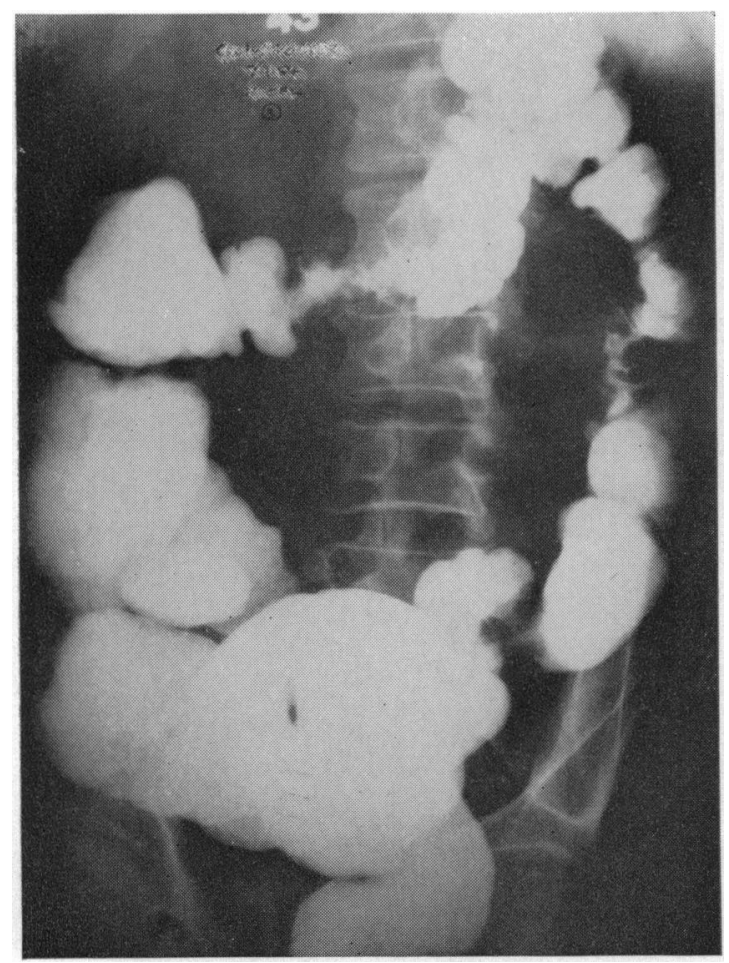

Fig. 9.-Case No. 17. Multiple localized strictures of the colon. caused by ulcerative colitis. In others, however, a different picture was seen; the mucosa was reddened and oedematous but not granular, and small scattered ulcers could be found (see Fig. 8). These ulcers varied in depth but often appeared infected with a little surrounding congestion, and the base was sometimes obscured by purulent discharge. In a few patients areas of granular bowel or of groups of ulcers were separated by areas of normal or slightly oedematous mucosa.

Radiological Appearances.-Most of this series of patients had had a barium enema examination carried out at some time, and many of them had also had a barium meal and follow-through. The radiological appearances naturally depend on the distribution and severity of the disease. As already mentioned, ulcerative colitis is a disease that nearly always extends in continuity, and the appearance of scattered areas of disease separated by normal parts is very suggestive of Crohn's disease, as is also the appearance of localized strictures of the bowel (Fig. 9). Disease that is more severe on the right side of the colon than on the left is more likely to be Crohn's disease than ulcerative colitis (Fig. 10).

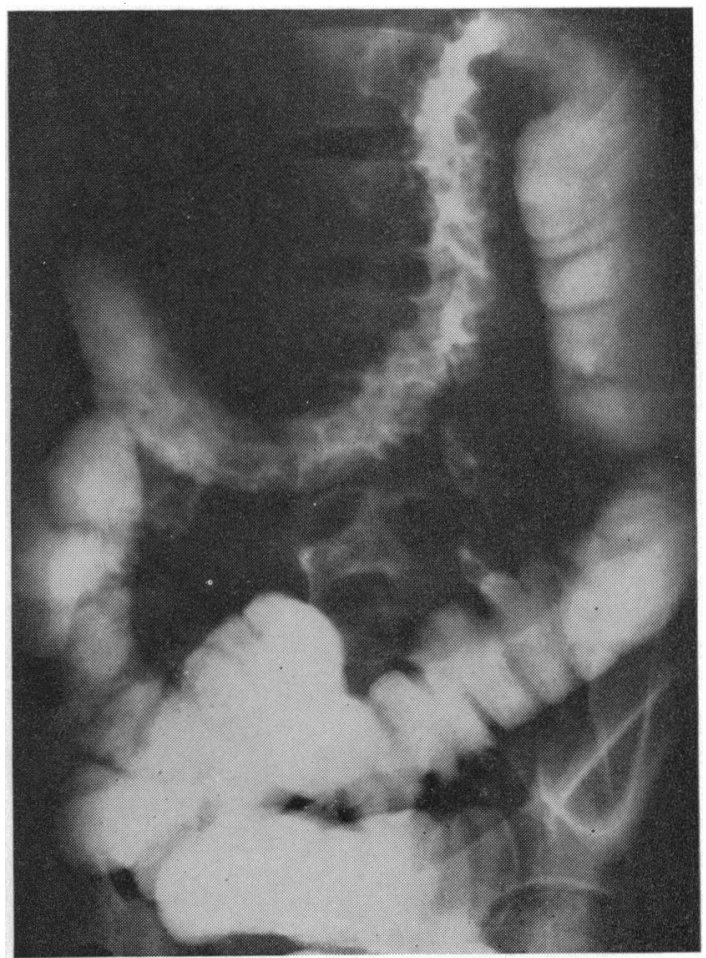

Fig. 10.-Case No. 6. Diffuse disease of the colon mainly confined to the right half. 
FIG. 11.-Case No. 19. Multiple strictures of the transverse colon with intervening normal mucosa.

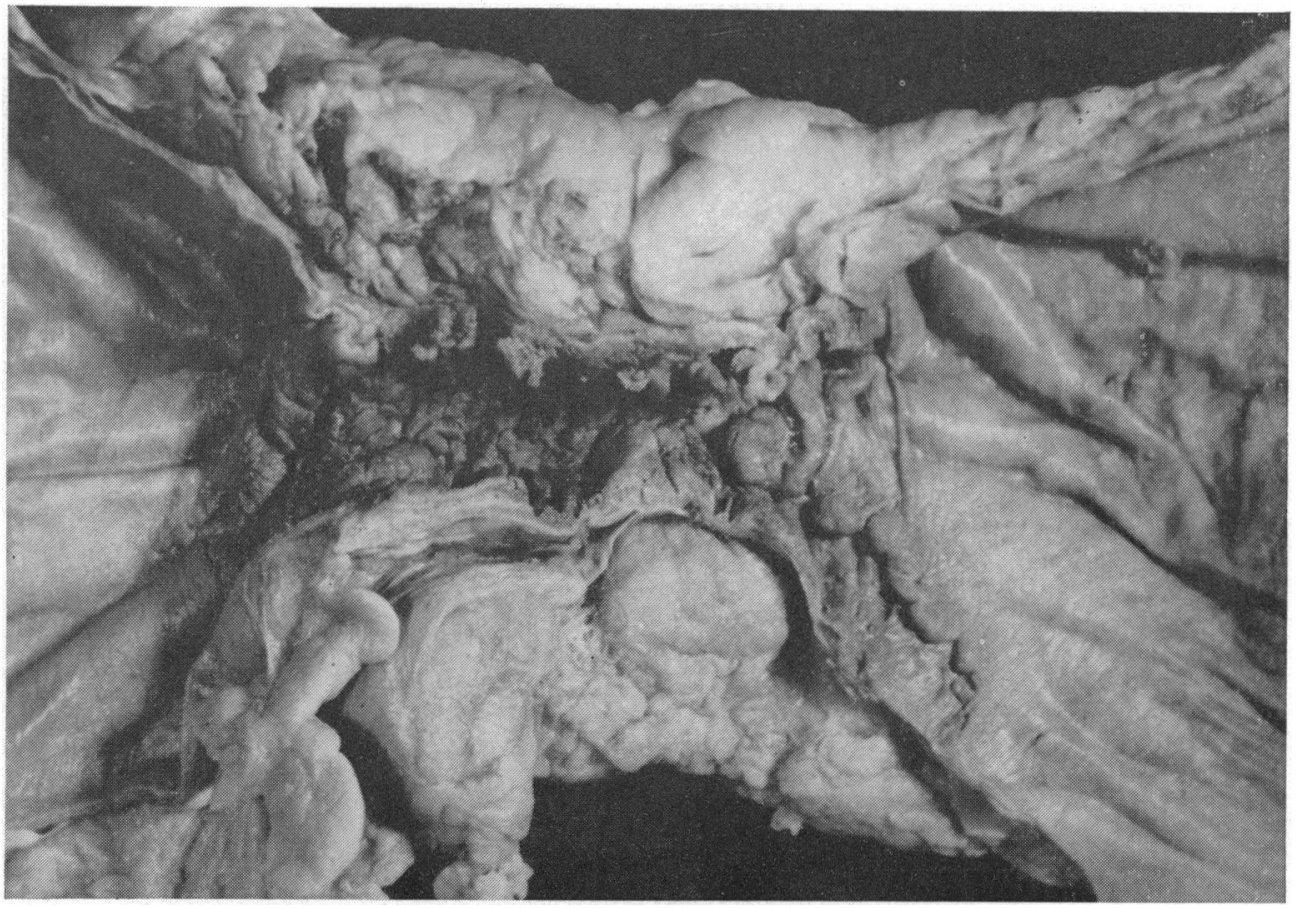

FIG. 12.-Case No. 17. Stricture of the colon resembling the "skip" areas seen in small intestinal disease. 
Reflux of a barium enema through the ileo-caecal valve which demonstrates narrowing of the terminal ileum as well as an abnormal colon suggests Crohn's disease, as the terminal ileum which becomes involved in the retrograde spread of ulcerative colitis is characteristically dilated. The clinical features of these cases do not differ greatly from group to group; diarrhoea, pain, bleeding, and loss of weight are symptoms common to most disorders of the large bowel. As sometimes occurs in cases of ulcerative colitis, the onset of severe symptoms followed an anal operation in three patients, for haemorrhoids in two and for excision of a fissure in one. We have pointed out that in many of these cases a diagnosis of ulcerative colitis or tuberculosis was made at some time during the illness, and often the correct diagnosis was not apparent until the bowel had been removed and the histology studied. However, with increasing experience, cases presented at this hospital in recent years have in several instances been correctly diagnosed before operation, and we believe that in many cases the diagnosis can be established on clinical and radiological grounds, aided when possible by biopsy.

\section{Pathology}

Appearances at Operation.-On opening the abdomen in a patient with Crohn's disease of the colon, the bowel usually appears obviously diseased. The external vascularity may be somewhat increased, and the peritoneal surface of the bowel may show signs of localized chronic inflammation with fibrosis and adhesions extending into the pericolic fat. A soft enlargement of the pericolic and ileocaecal lymph nodes is rather characteristic. The bowel feels thickened and rigid, and tiny "tubercles" may be seen on the peritoneal surface. In several of these cases it has been noted at operation that the spleen has been enlarged to two or three times its normal size.

Gross Appearances of Specimens.-In cases of Crohn's disease of the colon with diffuse disease of most or the whole of the large intestine, the appearances at first sight may resemble a case of ulcerative colitis, but careful examination reveals characteristics that are peculiar to Crohn's disease. In the first place, the ulceration is usually more sharply demarcated, and in all but one case there have been areas of intact intervening mucosa. This intervening mucosa may be lifted up to give the mammillated or nodular appearance which is seen so often in disease of the terminal ileum. In between these nodules small intercommunicating fissures may be found which penetrate deeply into the bowel wall and are the pathological basis of the intra- abdominal fistulae which often complicate intestinal Crohn's disease. In one of our colectomy specimens (Case 1, Fig. 3) the mucosal ulceration was very extensive and the surviving mucosa was markedly raised up to give the appearance of inflammatory polyposis. However, inflammatory polyposis is not a common feature of Crohn's disease of the colon as it is in ulcerative colitis.

In the operation specimens with single or multiple strictures the disease is well defined, involving a short segment of the bowel wall with fibrous thickening and narrowing of the lumen, and often ulceration (Fig. 11, Case 19). The adjacent mucous membrane is either normal or very slightly granular; the granular appearance can often be attributed to secondary infection from stasis of intestinal contents between areas of strictured bowel. The degree of thickening of the bowel wall in these cases varies with the chronicity of the disease. In specimens from patients with long-standing or "burnt-out" disease there may be very marked fibrous thickening with appearances similar to those seen in the "hose pipe" variety of classical Crohn's disease of the terminal ileum. The strictures in the colon closely resemble the "skip" areas so characteristic of small intestinal disease (Fig. 12, Case 17).

Fibrosis and oedema may be very pronounced in Crohn's disease and often extend into the pericolic fat (Fig. 13, Case 16). Enlargement of the regional nodes is marked and this is frequently a useful sign in the differential diagnosis from ulcerative colitis, in which enlargement of the nodes is not so striking.

The terminal ileum has been involved in seven of these 25 cases of Crohn's disease of the colon. The appearances of the terminal ileum in Crohn's disease have been fully described and there is no need to repeat them in detail here. The characteristic features are narrowing of the affected intestine with fibrous thickening of its walls and a nodular or mammillated appearance of the mucosa and some obvious mucosal ulceration. The ileocaecal valve is usually thickened but is visible as an obvious narrowing between small intestine and colon (Fig. 14, Case 6). In one specimen with disease of the distal sigmoid and rectum only, there was inflammatory ulceration and stenosis of the ileo-caecal valve but a normal terminal ileum (Case 21). In another with disease confined to the rectum there was isolated disease of the appendix (Case 20) which showed the histological appearance of Crohn's disease on microscopic examination. The appendix has been diseased in a number of other cases.

Microscopic Appearances.-Sections show that even in diseased areas the mucosal ulceration of the 


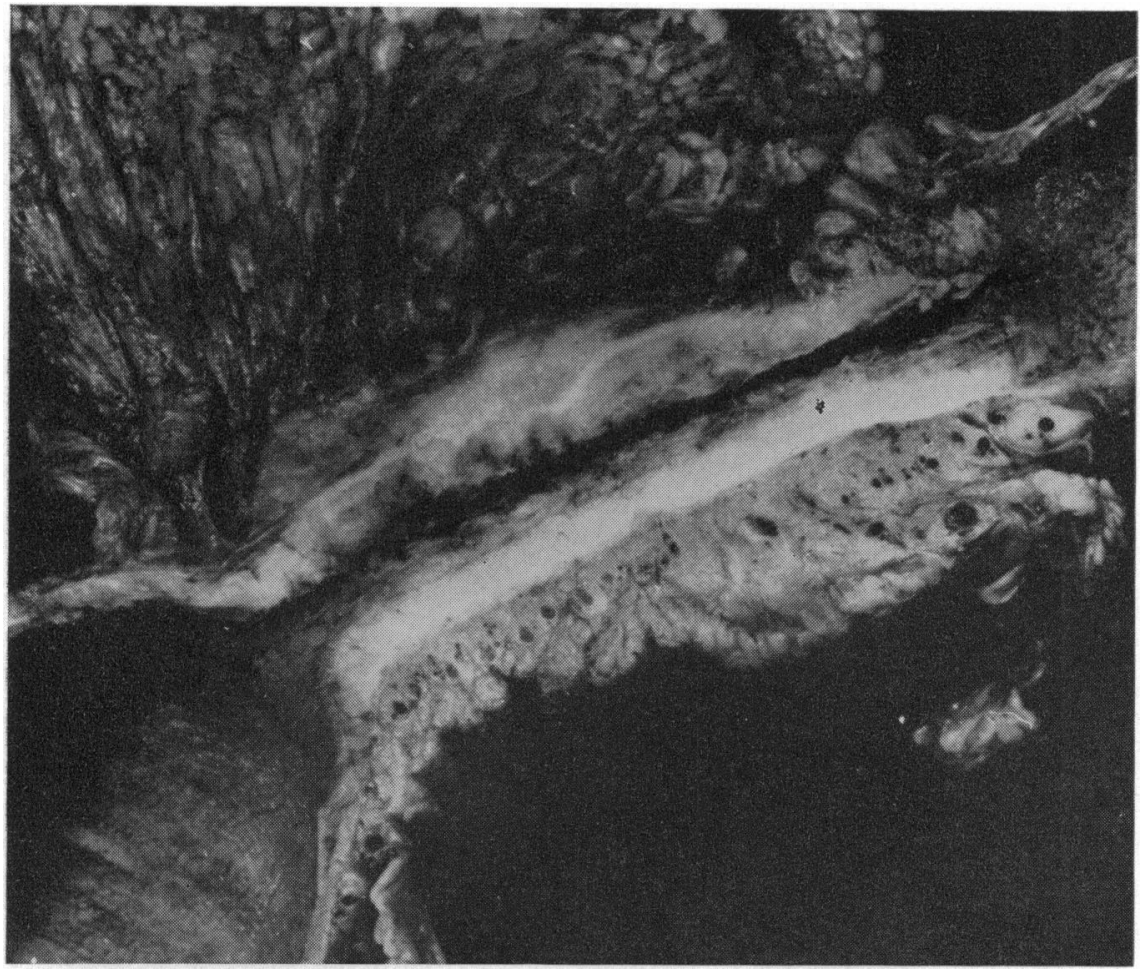

Fig. 13.-Case 16. Fibrous stricture of the splenic flexure with extension of the granulomatous process into the pericolic fat.

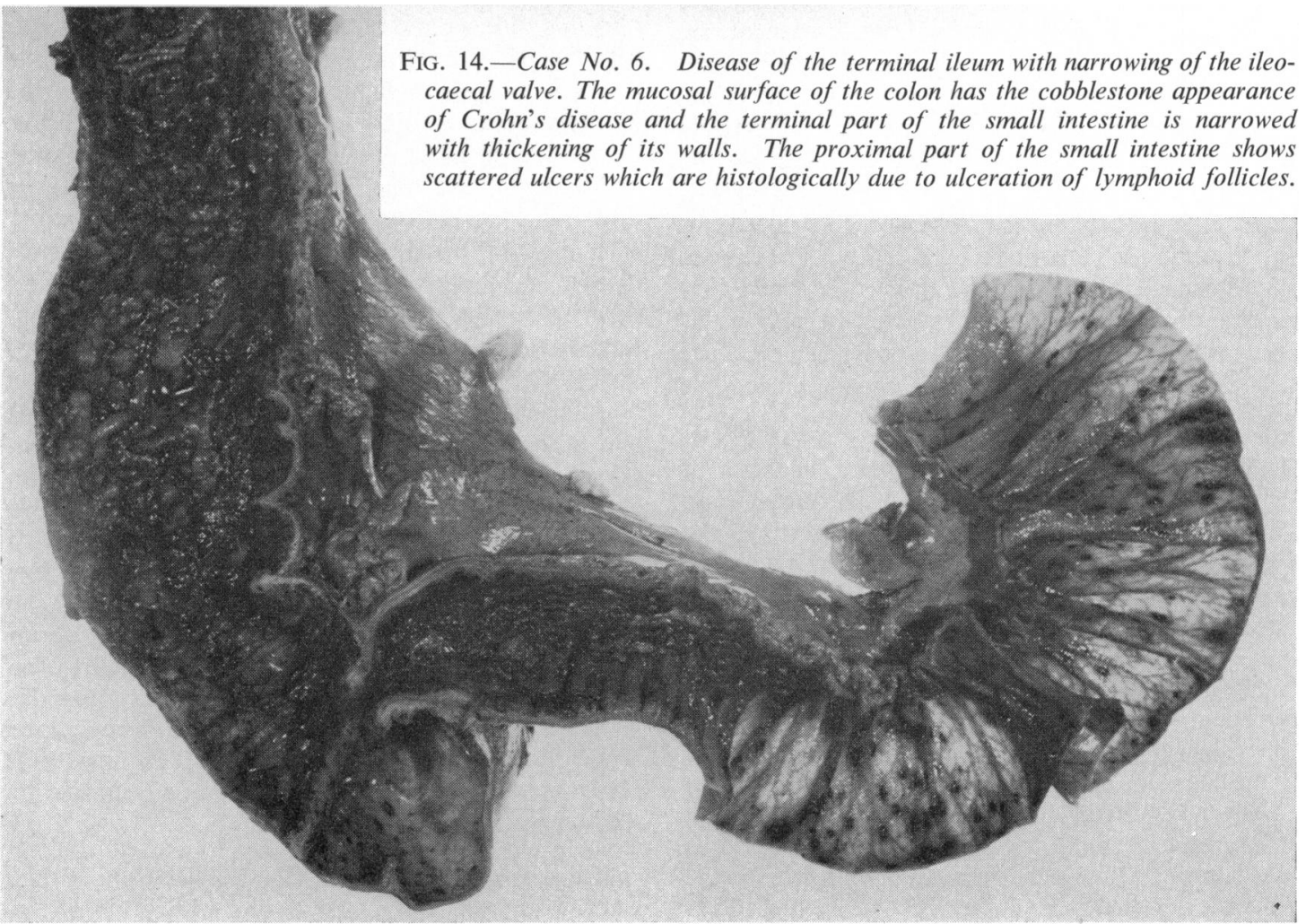

II. 14. - Case No. 6. Disease of the terminal ileum with narrowing of the ileowith thickening of its walls. The proximal part of the small intestine shows scattered ulcers which are histologically due to ulceration of lymphoid follicles. 
colon in Crohn's disease is patchy, the intervening mucosa being normal or nearly so. The ulceration extends into and along the submucosa and at a later stage through the muscularis externa into the serosa and pericolic fat. This deep ulceration or fissure formation, which can be seen with the naked eye as well as with the microscope, is the basis of the fistula formation which is characteristic of Crohn's disease.

Surrounding these fissures as they penetrate the bowel wall is a chronic granulomatous reaction with oedema, hyperplasia of lymphoid tissue, and fibrosis. This chronic granulomatous reaction is particularly prominent in the submucosa where it lifts up the mucous membrane between the areas of ulceration to give the nodular or mammillated appearance which is found in many cases of Crohn's disease, whether of the small or large intestine. In most of the cases of Crohn's disease of the colon the granulomatous reaction includes non-caseating giant-cell systems which are distributed through all layers of the bowel wall, as well as in the regional lymph nodes (Figs. 15 and 16). These giant-cell systems consist of one or more rather small multinucleated giant cells lying in a network of epithelioid cells mixed with mononuclear cells, principally lymphocytes. They are smaller than those in tuberculosis and never show central caseation, though a little central necrosis is occasionally seen. The giant-cell systems of Crohn's disease resemble sarcoid and may be justifiably referred to as a sarcoid reaction. But for the fact that patients with Crohn's disease never develop generalized sarcoidosis, it would be tempting to regard Crohn's disease and sarcoid as having a common aetiology. Moreover, in a few of our cases of Crohn's disease occasional giant cells have contained Schaumann and hyaline inclusion bodies identical with those seen in sarcoidosis (Fig. 17).

The discovery of giant-cell systems in these cases of Crohn's disease of the colon has been an important diagnostic feature, and they have been present in the majority of our cases. However, the distribution of the lymphoid hyperplasia, oedema, and fibrosis, together with the appearance of the mucosal ulceration and the formation of deep fissures in the bowel wall, make up a histological picture which can be diagnostic of Crohn's disease even in the absence of giant-cell systems. It is important to investigate many lymph nodes, taken from both the ileo-caecal and pericolic groups, for such systems. Their presence is not always related to the size of the glands and often very small nodes may be affected. The number of giant-cell systems in the bowel wall varies greatly and it is necessary in the investigation of a case of Crohn's disease of the colon to take pieces of tissue for section from several parts of the large intestine.

There is considerable evidence that Crohn's disease is a disease of lymphoid tissue. Certainly it is most common in the terminal ileum which has the largest aggregation of lymphoid tissue in the gastrointestinal tract. Histologically, the appearances suggest that the disease starts in the lymphoid follicles of the intestine with ulceration of the overlying mucosa and extension into the submucous tissue. In one of our cases the normal lymphoid follicle in a non-ulcerated part of the colon showed hypertrophy and contained giant-cell and epithelioid-cell systems (Fig. 18). In another case the earliest changes were apparently the result of ulceration of the lymphoid follicles and Peyer's patches in the terminal ileum. The granulomatous reaction is commonly related to the course of the blood vessels within the intestinal wall. It is possible that these granulomas occur within and around lymphatic vessels which are blocked and this is the cause of the marked oedema of the bowel wall and mesenteric tissues seen in active Crohn's disease.

\section{TREATMENT}

All 25 patients in this series have been treated surgically, but we do not suggest that they represent a fair sample of the disease generally. For one thing, as we have explained previously, these patients were selected in that only those in whom the diagnosis was regarded as certain and in whom good pathological material was available were included; moreover, patients are often referred to this hospital especially for surgical treatment. Many of these patients have at some time or other been treated medically, and good remission of the disease has occurred, either spontaneously or as a result of the medical treatment. It is likely that in many patients with Crohn's disease of the colon satisfactory remission and control of the disease for long periods can be obtained by medical treatment. Nevertheless, the patients in this series have either become severely ill or have developed complications such as strictures or fistulae and had not responded, or were no longer responding, to medical treatment.

Several different procedures have been employed in the treatment of these patients, and many patients have had more than one operation, sometimes as part of a deliberately staged procedure, sometimes because the first operation was not successful. Where possible, intestinal continuity has been restored, but in many cases an ileostomy or colostomy has been considered necessary for cure. So of these 25 patients, nine have had a total proctocolectomy and now have a permanent ileostomy; 


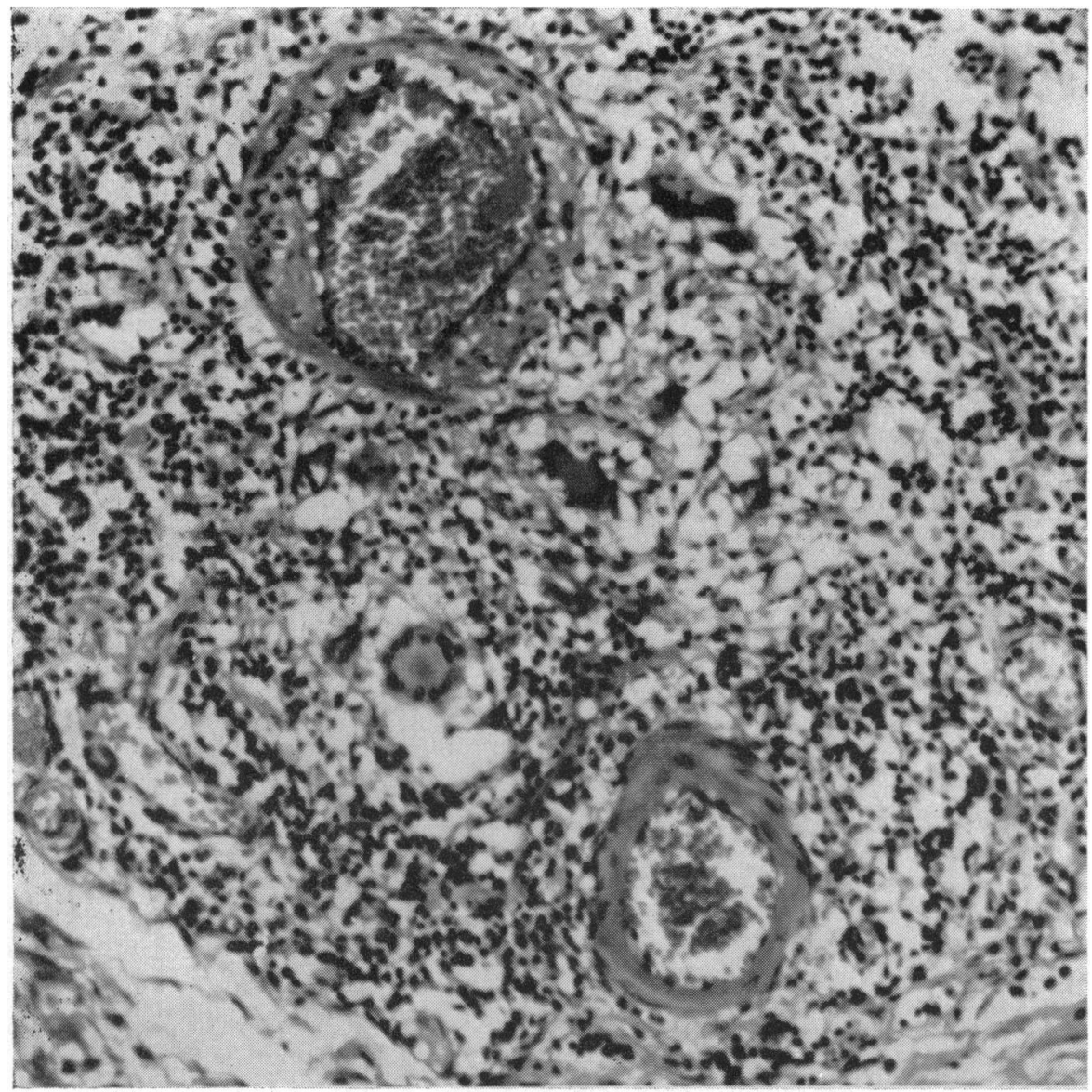

Fig. 15.-Granulomatous reaction in Crohn's disease showing the noncaseating giant cell system closely related to the course of blood vessels.

FIG. 16. - Non-caseating giant cell and epithelioid cell systems in a lymphatic gland. The appearances resemble sarcoid.

FIG. 17.-Crohn's disease of the colon. Schaumann and hyaline inclusion bodies within giant cells similar to those seen in sarcoidosis.

FIG. 18. - Collection of epithelioid cells and small giant cells in a lymphoid follicle of the colon from a case of large intestinal Crohn's disease.

FIG. 16

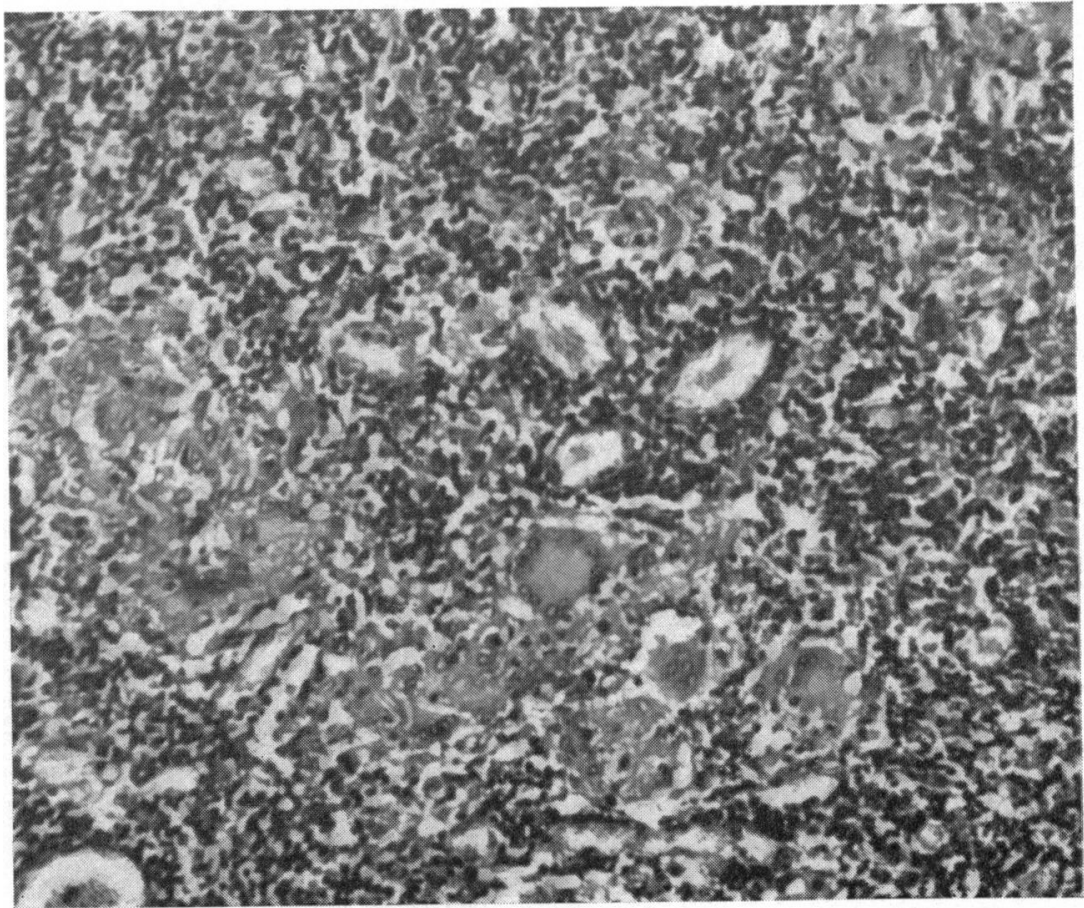



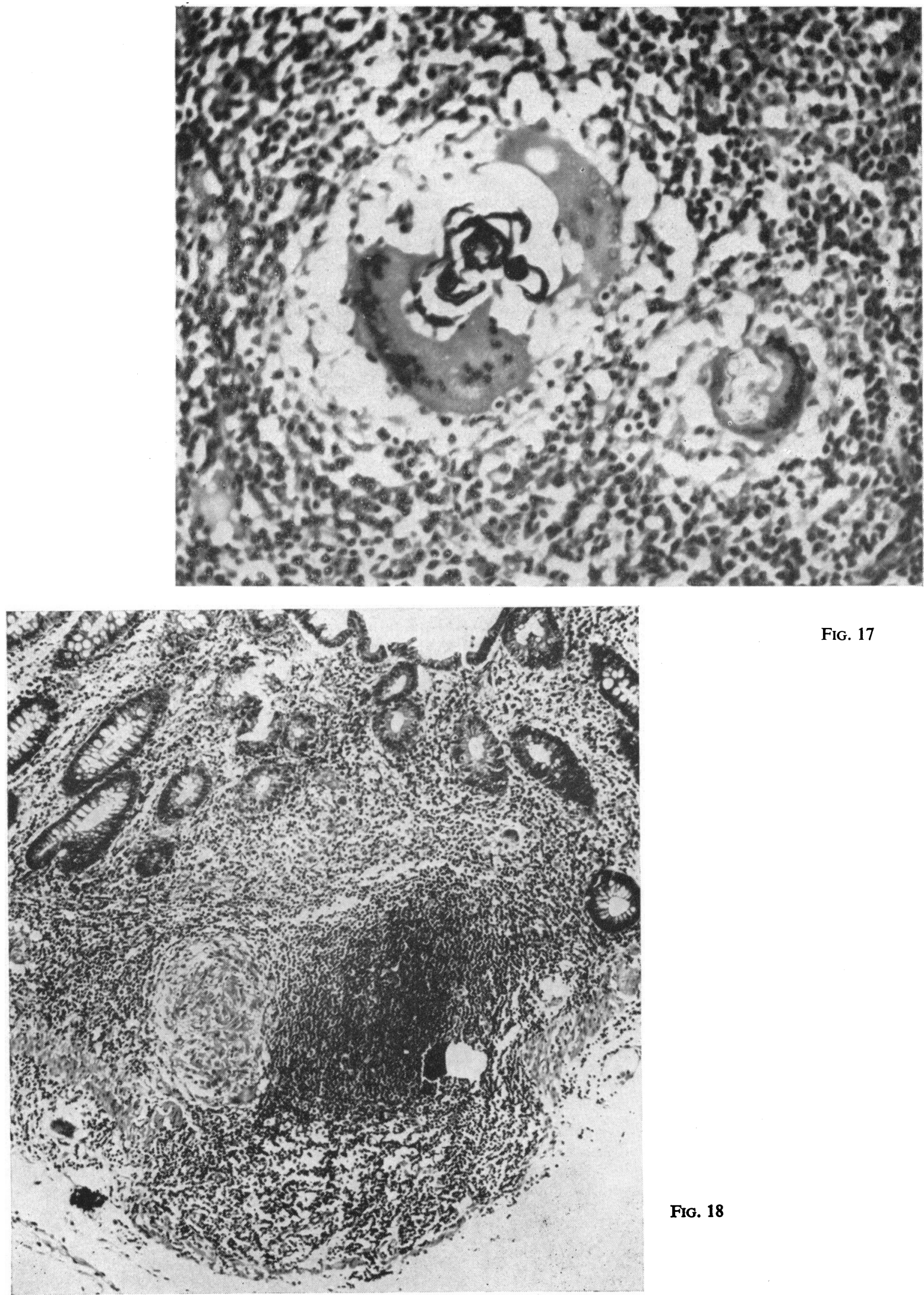

Fig. 17

Fig. 18

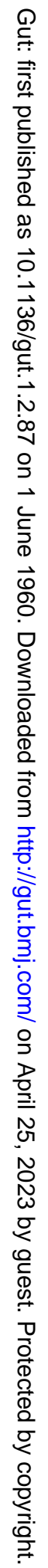


seven have had a colectomy with preservation of the rectum and ileo-rectal anastomosis; five have had an excision of the rectum with permanent inguinal colostomy; two have had a partial resection of the colon with anastomosis; and two have had an ileostomy with subtotal colectomy and await a further stage, possibly ileo-rectal anastomosis, perhaps excision of the rectum. There has been one death in these patients following surgery, a woman (Case 25) who died of shock and haemorrhage following an excision of the rectum and hysterectomy.

Complications following surgery have been those that one might expect in any series of major abdominal operations, except that indolence and slow healing of the perineal wound has been observed in four of the patients from whom the rectum was removed (13 operation survivors). We regard this as significant, as healing of the perineal wound is usually complete at this hospital in six to eight weeks after excision of the rectum, while in these patients it took six months or longer. Biopsies were taken from these indolent perineal wounds and in one of them giant-cell systems, similar to those previously found in the bowel, were found. Nevertheless, sound healing finally took place in these four patients.

We have kept in touch with all these patients after surgery to see how they have progressed, and most of them attend at regular intervals as outpatients. It appears that the results after excision of the affected bowel have been good, whereas those following faecal diversion without removal of the diseased bowel have usually been bad. Thus, all patients who have had a total colectomy and ileostomy are well, the elapsed time since operation varying from one to five years. Five of the patients treated by ileo-rectal anastomosis are perfectly well, but in two there is some residual proctitis; one has had a recurrence of an old anal fistula. However, no further surgery for these two patients is contemplated at the moment as they are in good health. The four patients who had an excision of the rectum only are well, two for five years, one for three years, and one was only treated one year ago. One of the patients treated by a localized resection of the colon had to have a further operation later because of disease in the rectum (Case 14) but the other has remained well.

On the other hand, seven patients had at some time a diversion operation with the hope of inducing remission of active disease. Five had had a colostomy (Cases 12, 20, 21, 23, and 24) and two an ileostomy (Cases 10 and 25). Only one of these patients did well after diversion alone; this young man (Case 10) fully regained his health and put on a lot of weight after ileostomy, though continued activity and discharge from the defunctioned but diseased bowel was considered sufficient reason, a few years later, for its removal. The other six patients were not benefited by diversion of faeces. Active disease in the bowel persisted in spite of continued medical treatment, their health did not improve, and they were only restored to health by excision of the diseased bowel, since when they have remained well. However, we should say here that we know of two further patients at this hospital with Crohn's disease of the colon in whom an ileostomy was done, in both of whom dramatic improvement took place, though colectomy may later become necessary. (They are not included in the series because no specimen was available for pathological study.)

From a study of these cases and from others seen at the hospital, we get the impression that in Crohn's disease affecting the large bowel medical measures have not been very successful and that surgery seems to offer a better prospect of a return to normal health and of prolonged freedom from disease. As in most clinics, the practice at St. Mark's Hospital in cases of ulcerative colitis in which medical treatment has failed has been to excise the colon: usually ileostomy and total proctocolectomy in one or two stages is done, with preservation of the rectum and ileo-rectal anastomosis in certain selected cases. In Crohn's disease of the large intestine, however, we consider that localized resection of the diseased part of the bowel with anastomosis is desirable where possible; if this is not possible, we think that a diversion operation only (ileostomy or colostomy) may have a place and should be tried in the first instance.

With such a small series of cases and with a longest follow-up of only five years, it would be unwise to be dogmatic. Nevertheless, the results of excisional surgery have been encouraging so far. We hope that experience may show that Crohn's disease of the colon has a lesser tendency to recur after excisional surgery than does Crohn's disease affecting the small bowel.

\section{Discussion}

There is much confusion over the relationship between Crohn's disease and ulcerative colitis. The literature contains reports of Crohn's disease of the terminal ileum with disease of the colon regarded by the authors as the simultaneous occurrence of two separate conditions, namely Crohn's disease and ulcerative colitis. It is recognized, however, that Crohn's disease may affect the colon, though this is thought to be rare. Yarnis (1958) presents 64 cases 
of "ileo-colitis", and of these he regards 60 as being a combination of granulomatous ileitis and ulcerative colitis (which he calls "combined ileocolitis") and only four as examples of granulomatous ileo-colitis. Daffner and Brown (1958) report a series of 100 cases of Crohn's disease and record that $37 \%$ of them had "ileo-colitis", but do not describe the pathology of these cases. French and Vander (1955) discuss ulcerative colitis and "regional entero-colitis", but do not make a clear distinction between the two conditions. Warren and Sommers (1954) consider that the simultaneous occurrence of Crohn's disease and ulcerative colitis is very rare, and a similar opinion is expressed by Otani (1955), writing from the Mount Sinai Hospital, who regards such an association as coincidental. There is, therefore, a good deal of controversy in the published literature as to the frequency of association of these two diseases and whether Crohn's disease may give rise to pathological changes in the colon similar to those found in the terminal ileum.

We have never seen Crohn's disease and ulcerative colitis in the same patient, and believe that when Crohn's disease of the terminal ileum coexists with ulceration in the colon, histological examination will reveal that the colonic lesions have the same pathology as the Crohn's disease in the small intestine. Moreover, it does not seem to be fully appreciated that Crohn's disease may affect the large bowel without any disease in the small intestine, and may even be confined to the rectum and distal sigmoid colon.

Crohn's disease of the colon may be differentiated from ulcerative colitis on clinical, radiological, and pathological evidence. The main features have already been described from the clinical, radiological, and pathological aspects, and it must be emphasized that the final distinction between Crohn's disease of the colon and ulcerative colitis does not rest on any one feature, macroscopic or microscopic, but on the overall appearance taken in conjunction with the clinical findings. In view of the difficulty in distinguishing between the two diseases, it may be helpful to emphasize the points of difference rather than the features which they possess in common.

In ulcerative colitis it is commonly the left side of the colon which shows the more advanced disease. Often the right side shows only relatively early changes and the caecum and ascending colon may often be normal in size or slightly dilated. On the other hand, a predominantly right-sided colitis with ileal involvement is more likely to be due to Crohn's disease than to ulcerative colitis, especially in the presence of a normal rectum. A particular point of distinction between the two diseases is that frequently in Crohn's disease the mucosal changes are discontinuous with areas of intervening normal mucosa, whereas in ulcerative colitis the disease is diffuse, although here again there may be a relatively normal area on the right side of the colon separating the diffuse disease on the left from an area of disease in the caecum. However, in cases of Crohn's disease one frequently sees small scattered ulcers throughout the bowel with areas of normal mucosa between them, and this is never seen in cases of ulcerative colitis, where if the ulcers are scattered, the mucosa between them is always abnormal, congested, and granular.

Microscopically, the main difference between Crohn's disease and ulcerative colitis is that in the former there is a granulomatous reaction extending through all layers of the bowel wall, whereas in colitis the inflammation is superficial and confined to the mucosa in the first place, with some later extension into the submucous tissue, but never any penetration of the muscularis externa except as the result of perforation in the acute fulminating form of the disease. Moreover, the intramural fissures of Crohn's disease are not seen in ulcerative colitis. Another important feature is that in cases of colitis the thickening of the bowel wall is due to muscular hypertrophy and spasm rather than to fibrosis (McGovern and Archer, 1957). Even in patients with a long history of severe and extensive ulcerative colitis, there is relatively little reactive fibrosis. There may be some increase in the submucous fibrous tissue but this is out of proportion to the intensity of the inflammation. On the other hand, Crohn's disease is very much a fibroustissue-producing condition and is classified among the chronic granulomatous diseases; and in cases of Crohn's disease of the colon considerable fibrosis can be found in the deeper layers of the bowel wall. However, the most striking histological feature which helps to differentiate the two diseases on microscopic examination is the giant-cell granuloma of Crohn's disease. It must be emphasized that these giant cells are not morphologically like foreign-body giant cells. Moreover, they are part of a giant-cell system and are not in any way isolated from their neighbouring cellular elements. They must be distinguished from the occasional foreign-body giant cell seen near the surface of the ulcers in chronic ulcerative colitis.

The distinction between chronic ulcerative colitis and Crohn's disease can sometimes be aided by rectal biopsy. In a few cases in this series a biopsy was taken from the rectum before operation and revealed non-caseating giant-cell systems in the rectal submucosa accompanied by a chronic 


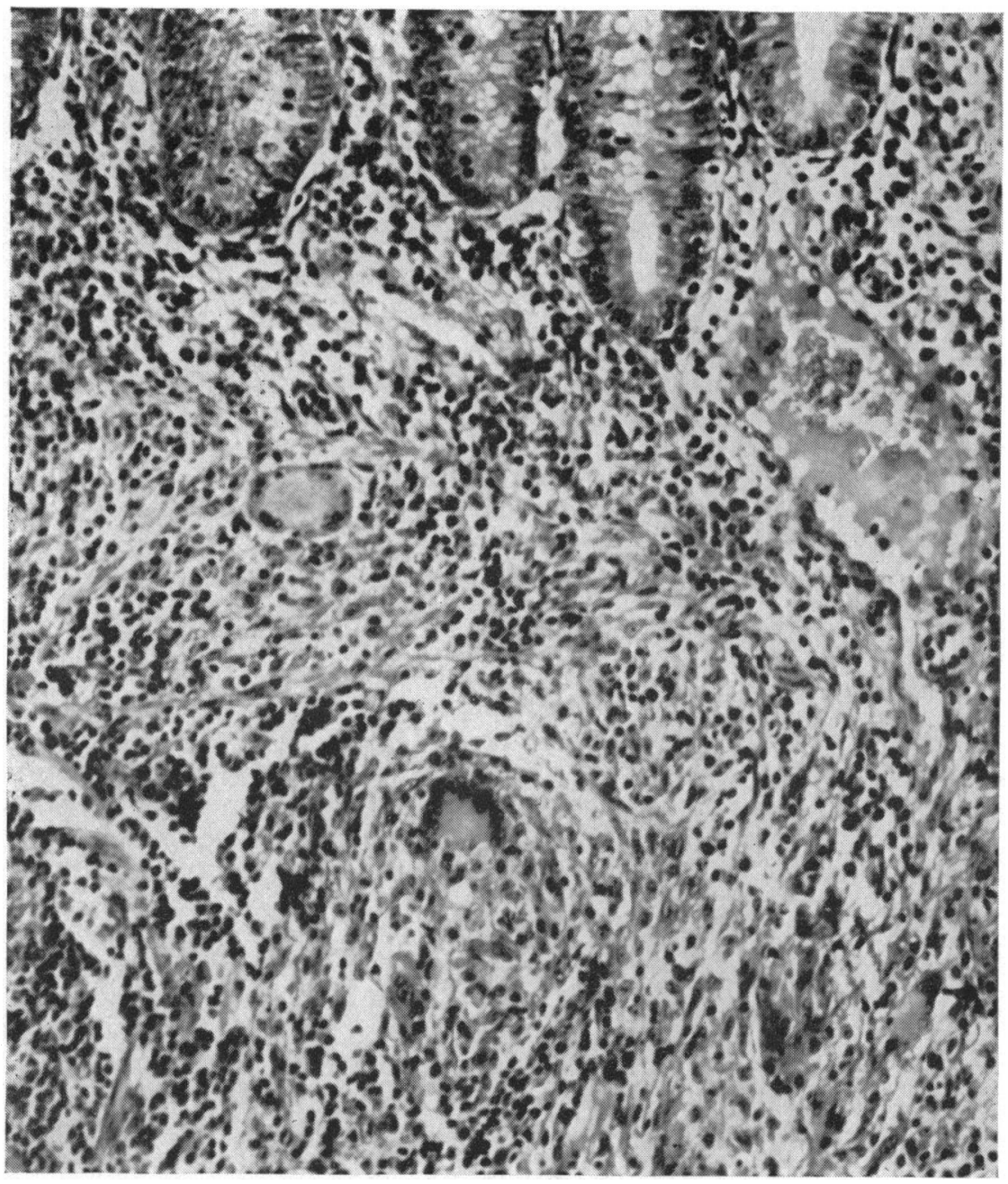

FIG. 19.-Biopsy of a rectal lesion of diffuse Crohn's disease of the large intestine showing agranulomatousprocess in the submucosa with proliferation of epithelioid cells and a Langhams type giant cell.

granulomatous reaction which was primarily submucous in its distribution (Fig. 19). The presence of giant-cell systems in a rectal biopsy should be reported as no more than suggestive of Crohn's disease and used in conjunction with other clinical and radiological features in contributing towards an accurate diagnosis. The histological examination of biopsy material from anal lesions such as ulcers, fissures, or fistulae, which commonly complicate Crohn's disease, will reveal non-caseating giant-cell systems identical with those found in the intestinal lesion in a high proportion of cases. In a previous paper (Morson and Lockhart-Mummery, 1959b) we have reported our experience with these anal lesions in cases of Crohn's disease. Although a few patients with chronic ulcerative colitis also develop anal lesions, the finding of giant-cell systems in anal biopsy material from a patient with inflammation of the large bowel may be helpful in distinguishing between chronic ulcerative colitis and involvement of the colon with Crohn's disease.

Ulcerative colitis and Crohn's disease of the large intestine have also to be distinguished from the ileo-colitis of Cooke and Brooke as well as from tuberculosis, and from certain cases of regional or segmental colitis as well as other specific diseases of the large intestine mentioned at the beginning of this paper. A special variety of "ileo-colitis" was first described by Brooke and Cooke in 1951 and again by the same authors in 1955 (Cooke and Brooke, 1955). The condition is characterized by diarrhoea, steatorrhea, and anaemia, with ulcers in the small bowel later spreading to involve the colon, extending from the ileo-caecal valve distally. At the moment the pathology of this condition is not clear and as an entity it is not fully accepted by gastro- 
enterologists. Though tuberculosis affecting the ileo-caecal region is much rarer than Crohn's disease in this country, it may still occur (Thompson and Morson, 1958). Three such cases are reported by Pollock (1958) who draws attention to Anand's (1956) experience that giant-cell systems in the intestinal wall are not a constant feature of such cases, and that even if they do occur, central caseation in them is not the rule; Anand does say, however, that giant-cell systems with caseation are constantly found in the regional lymph nodes. These observations emphasize the importance of a careful search for caseation and tubercle bacilli in multiple sections of both the bowel wall and related lymph nodes before a certain diagnosis of Crohn's disease is given. "Regional" colitis is a difficult condition to define and has been the subject of many papers in the literature, and has recently been discussed by Watkinson and Goligher (1959). We believe that many cases that have been regarded as "regional colitis" are really examples of Crohn's disease, and many of those in our Group 2 and a few in Group 1 might have been so regarded. Nevertheless, there are still patients with localized lesions of the colon with no definite evidence of Crohn's disease which must, in the absence of more knowledge, be called for the time being "regional colitis". In the last year we have seen two such cases in clinical practice. One patient had a very localized fibrous stricture in the descending colon in which no specific histology was discovered, and the other had a $6 \mathrm{in}$. area of stenosis in the transverse colon with linear ulceration and with histology suggestive of ulcerative colitis, but with the rest of the bowel entirely normal. Cases such as this, and many of those in the paper reported by Watkinson and Goligher, must still be regarded as cases of "regional colitis", and in all of them the rectum was normal on sigmoidoscopy. We consider that this group of patients requires special study as it is likely that diseases of different pathology are still being grouped together under this heading.

We wish to thank the surgeons of St. Mark's Hospital for permission to use their case histories; also the staff of the Research Department for their help and to the Board of Governors of the Hammersmith and St. Mark's Group of Hospitals for a research grant.

\section{REFERENCES}

Anand, S. S. (1956). Ann.roy.Coll. Surg. Engl., 19, 205.

Brooke, B. N. (1959). Lancet, 2, 745.

- , and Cooke, W. T. (1951). Ibid., 2, 462.

Cooke, W. T., and Brooke B. N. (1955). Quart. J. Med., 24, 1.

Crohn, B. B., Ginzburg, L., and Oppenheimer, G. D. (1932). J. Amer. med. Ass., 99, 1323.
and Rosenak. B. D. (1936). Ibid., 106, 1.

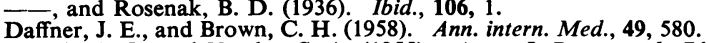

French, A. J., and Vander, S. A. (1955). Amer. J. Roentgenol., 74, 977.

Goldgraber, M. B., and Kirsner, J. B. (1958). A.M.A. Arch. intern. Med., 102, 134 .

-, Med, and Palmer, W. L. (1959), Proc. World Congress Gastroenterol. Washington, 1958, Vol 2, p. 935 .

Hadfield, G. (1939). Lancet, $2,773$.

McGovern, V. J., and Archer, G. T. (1957). Aust. Ann. Med., 6, 68.

Morson, B. C., and Lockhart-Mummery, H. E. (1959a). Gastroenterologia (Basel), 92, 168.

Otani, S. (1955). J. Mt Sinai Hosp., $22,147$.

Pollock. A. V. (1958). Brit. J. Surg., 46, 193.

Thompson, H. R., and Morson, B. C. (1958). Proc. roy. Soc. Med., $5,1246$.

Warren, R., and McKittrick, L. S. (1951). Surg. Gynec. Obstet., 93,555 .

Warren, S., and Sommers, S. C. (1954). J. Amer. med. Ass., 154, 189 Watkinson, G., and Goligher, J. C. (1959). Gastroenterologia (Basel) 92, 157.

Wells, C. (1952). Ann. roy. Coll. Surg. Engl., 11, 105.

Yarnis, H. (1958). In Regional Ileitis, 2nd ed. by B. B. Crohn and H. Yarnis. Grune and Stratton, New York and London. 